\title{
Hereditary nephrogenic diabetes insipidus in Japanese patients: analysis of 78 families and report of 22 new mutations in AVPR2 and AQP2
}

\author{
Sei Sasaki $\cdot$ Motoko Chiga $\cdot$ Eriko Kikuchi · \\ Tatemitsu Rai $\cdot$ Shinichi Uchida
}

Received: 15 October 2012/ Accepted: 28 October 2012/Published online: 14 November 2012

(C) Japanese Society of Nephrology 2012

\begin{abstract}
Background Familial form of nephrogenic diabetes insipidus (NDI) is a rare hereditary disease caused by arginine vasopressin type 2 receptor (AVPR2) or water channel aquaporin 2 (AQP2) gene mutations. It is speculated that $90 \%$ of NDI families carry disease-causing mutations in AVPR2 and $10 \%$ carry the mutations in AQP2; however, these percentages have not been supported by actual data. It is also unknown whether these percentages vary in different ethnic groups.

Methods Gene mutation analyses were performed for 78 Japanese NDI families. All exons and intron-exon boundaries of the AVPR2 and AQP2 genes were directly sequenced.

Results A total of 62 families (79\%) carried diseasecausing mutations in AVPR2, while nine families (12\%) carried mutations in AQP2. We identified 22 novel putatively disease-causing mutations (19 in AVPR2 and 3 in AQP2). Regarding AVPR2, 52 disease-causing mutations were identified. Among them, missense mutations were most common ( $54 \%$ ), followed by deletion mutations. In the 64 women who had monoallelic disease-causing AVPR2 mutations, 16 (25\%) had NDI symptoms, including 4 complete NDI subjects. Regarding AQP2, 9 disease-causing mutations were identified in nine families. Two missense mutations and one deletion mutation showed a recessive inheritance, while one missense mutation and five small deletion mutations in the C-terminus of AQP2 showed a dominant inheritance.
\end{abstract}

S. Sasaki $(\bowtie) \cdot$ M. Chiga $\cdot$ E. Kikuchi - T. Rai · S. Uchida Department of Nephrology, Graduate School of Medical and Dental Sciences, Tokyo Medical and Dental University, 1-5-45 Yushima, Bunkyo-ku, Tokyo 113-8519, Japan e-mail: ssasaki.kid@tmd.ac.jp
Conclusions Most Japanese NDI families carry diseasecausing mutations in AVPR2 and $12 \%$ carry mutations in AQP2. A total of 22 novel putatively disease-causing mutations were identified. The relatively high occurrence of symptomatic carriers of AVPR2 mutations needs attention.

Keywords Aquaporin 2 - Urine concentration · Vasopressin · Vasopressin receptor · Kidney collecting duct

\section{Introduction}

Nephrogenic diabetes insipidus (NDI) is a human kidney disease in which the urine-concentrating ability of the kidney cannot respond to the antidiuretic hormone, arginine vasopressin, resulting in the massive excretion of diluted urine. Therefore, NDI patients manifest polyuria and polydipsia. The hereditary (congenital) form of NDI is relatively rare, and is known to be caused by mutations in two genes, the arginine vasopressin type 2 receptor (AVPR2) and the water channel aquaporin 2 (AQP2) [1-4]. These two genes encode two membrane proteins that are oppositely located at the basolateral and apical membranes of the collecting duct principal cells, respectively, and constitute the fundamental components of urine concentrating machinery $[5,6]$.

The AVPR2 gene is located ion X chromosome (Xq28), and thus, NDI caused by AVPR2 gene mutations is transmitted in an X-linked recessive mode (OMIM 304800); males with one mutated gene are symptomatic, whereas heterozygous females are usually asymptomatic. The AQP2 gene is located on chromosome 12 (12q13.12), and NDI caused by AQP2 mutations shows both autosomal 
recessive and dominant inheritance (OMIM 125800, 107777) [7, 8]. Several review papers have claimed that about $90 \%$ of NDI patients carry AVPR2 mutations and about $10 \%$ carry AQP2 mutations; however, actual data in support of this estimate have not been shown [1, 3]. It is also unknown whether the genetic causes of NDI vary among different ethnic groups.

After the cloning of human AQP2 [9] and the first report of an NDI patient with mutated AQP2 [10], we have performed gene mutation analyses of Japanese NDI patients. At the end of July 2012, the total number of analyzed NDI families was 78, a significant number which may provide some insights into the genetic causes of hereditary NDI.

\section{Materials and methods}

All NDI families included in this study were referred to our department or visited our outpatient clinic for analysis of gene mutations. Diagnosis of NDI was made in individual facilities based on family histories, clinical symptoms (polyuria and polydipsia, fever due to dehydration), laboratory data (urine and serum osmolalities, serum sodium, serum vasopressin), and responses to water deprivation and/or vasopressin administration. Subjects who presented a milder form of NDI (partial NDI), such as having weaker responses to water deprivation and/or vasopressin administration, were included in this study. Written informed consent for gene mutation analysis was obtained in individual facility. Mutation analyses were performed in our laboratory for most families. Some earlier cases were analyzed in Daniel Bichet's laboratory in Montreal and reported previously [11]. Also, several cases have been reported separately before [12-16]. The AVPR2 and AQP2 genes are relatively small and all exons and intron-exon boundaries were sequenced with usual sequencing methods [12, 17, 18]. Usually, mutation analysis of AVPR2 was performed first. If no causative mutations were found, then AQP2 was analyzed.

\section{Results and discussion}

Causative genes in Japanese NDI families

A total of 78 families were referred to us and gene mutation analyses were performed for the AVPR2 and AQP2 genes (Table 1). Gene mutations that presumably cause NDI were identified in the AVPR2 gene in 62 families (79\%), and in the AQP2 gene in nine families (12\%). In the remaining seven families, no mutations were detected in either the AVPR2 or AQP2 genes (Table 1). Of these 78 families, 62 families were newly examined and reported in
Table 1 Causative genes in Japanese Nephrogenic diabetes insipidus (NDI) families

\begin{tabular}{ll}
\hline Causative genes & Number of families \\
\hline$A V P R 2$ & $62(79 \%)$ \\
New in this report & 49 \\
Previously reported & 13 \\
$A Q P 2$ & $9(12 \%)$ \\
New in this study & 6 \\
Previously reported & 3 \\
Not found & $7(9 \%)$ \\
Total & 78 \\
\hline
\end{tabular}

this paper. A total of 22 novel putatively disease-causing mutations that have not been previously reported or included in the public database (HGMD: http://www.hgmd. cf.ac.uk/ac/index.php) were identified in this study (19 in AVPR2 and 3 in AQP2).

If the seven families with no mutations are excluded, AVPR2 accounts for $87 \%$ of gene defect-identified cases, while AQP2 accounts for $13 \%$. These data provide clear evidence for the general assumption that $90 \%$ of cases are caused by AVPR2 and $10 \%$ are caused by AQP2 mutations [1, 3]. These data also indicate that the genetic mechanisms for congenital NDI are the same in the Japanese population.

More than 220 disease-causing mutations have been reported for AVPR2 [19], and 50 disease-causing mutations have been reported for AQP2 [7, 20]. Our present report of 22 new putatively disease-causing mutations significantly increases the numbers of known NDI-causing mutations by about $10 \%$. When new mutations are found, it must be determined if they are disease causative or not. This determination is usually done by examining associations between the genotype and phenotype within the family (a comparison of subjects harboring the mutation and expression of clinical symptoms) and by examining functions of the mutated gene product in heterologous expression systems. In the present study, the functions of the mutant proteins were not examined, which is a limitation of the present study.

Disease-causing AVPR2 mutations in 62 NDI families

A total of 52 putative disease-causing AVPR2 mutations were identified in 62 families (several mutations were shared by different independent families). Table 2 summarizes the types of AVPR2 mutations. Gene variants/ polymorphisms that have been reported not to cause NDI [19] were excluded in this summary. Missense mutations were most common, accounting for half of the mutations, followed by deletion mutations, insertion mutations, and 
nonsense mutations. Splicing mutations were the least common. This relative frequency of disease-causing AVPR2 mutations is consistent with the results of a worldwide summary of AVPR2 mutations, as shown in Table 2 [19], again confirming that the genetic mechanisms causing NDI are the same in different ethnic groups [19].

Of these AVPR2 mutations, 19 mutations were novel, and the other mutations were previously reported or recurrences of the previously reported mutations. Details of the novel AVPR2 mutations are summarized in Table 3. In brief, in a family carrying the missense mutation D85E, an index subject was a female patient manifesting complete NDI, and her father also manifested NDI. The index subject was heterozygous for this mutation. The codon Asp85 seems functionally important, because another missense mutation on this residue, D85N, was reportedly causative in six families [19]. L90P was observed in two unrelated families. In one family, the index case was a mother of a boy with NDI; they manifested partial and complete NDI, respectively, and the mother was a heterozygous carrier of the mutation. In another family, a boy showed complete NDI, and his mother was a heterozygous carrier of the mutation with no NDI symptoms. K116N mutation was found in a boy with complete NDI, and his mother was not a carrier of the mutation, implying that the mutation occurred de novo. M123R mutation was observed in two unrelated families in which the index patients were boys with complete NDI. DNA samples of other members of the families were not available, and a mother in one family had polyuria and polydipsia. M123R has not been previously reported, but another mutation on this residue, $\mathrm{M} 123 \mathrm{~K}$, has been reported [11]. L131P were found in two young brothers with complete NDI, and their mother was a heterozygous carrier of the mutation with no NDI symptoms. Mutation on Leu131 has not been reported, but missense mutations on encompassing residues, I130L, I130F and A132D have been shown to be causative [19], indicating that this region is functionally important. W164R was found in a boy with NDI, and his mother was a heterozygous carrier of the mutation. On Trp164, another mutation, $\mathrm{W} 164 \mathrm{~S}$, has been reported [17], and mutations on Ala165 and Ser167 were also shown to be causative [19]. Q225R was found in a boy with complete NDI, and his mother was a heterozygous carrier without symptoms, while his healthy brother was not affected. L316R was found in a boy with complete NDI, and his mother was a heterozygous carrier. Leu316 has not been the target of missense mutations, while encompassing residues Ser315 and Asn317 located in the 7th transmembrane domain of AVPR2 protein are the target of disease-causing mutations, S315R and N317K [19]. S329G was found in a boy with complete NDI. His mother and grandmother were asymptomatic heterozygous carriers of the mutation, and his uncle had the same
Table 2 Types of AVPR2 mutations in Japanese Nephrogenic diabetes insipidus (NDI) patients and comparison with a global summary

\begin{tabular}{lll}
\hline $\begin{array}{l}\text { Types of } \\
\text { mutations }\end{array}$ & $\begin{array}{l}\text { Number of mutations } \\
\text { identified in Japanese patients }\end{array}$ & $\begin{array}{l}\text { Relative frequency in } \\
\text { a global summary }^{\mathrm{b}}(\%)\end{array}$ \\
\hline Missense & $28(54 \%)$ & 56 \\
Nonsense & $4(8 \%)$ & 13 \\
Deletion & $13(25 \%)$ & 29 \\
Insertion & $5(10 \%)$ & 4 \\
Splicing & $2(4 \%)$ & 1 \\
\hline
\end{tabular}

${ }^{a}$ A total 52 mutations were identified in this study

b Relative frequency reported by Spanakis et al. [19]

Table 3 New putative disease-causing AVPR2 mutation

\begin{tabular}{|c|c|c|}
\hline & Nucleotide change & $\begin{array}{l}\text { Amino acid } \\
\text { change }\end{array}$ \\
\hline \multirow[t]{10}{*}{ Missense } & c. $255 \mathrm{C}>\mathrm{A}$ & $\mathrm{D} 85 \mathrm{E}$ \\
\hline & c. $269 \mathrm{~T}>\mathrm{C}$ & L90P \\
\hline & c. $348 \mathrm{G}>\mathrm{C}$ & $\mathrm{K} 116 \mathrm{~N}$ \\
\hline & c. $368 \mathrm{~T}>\mathrm{G}$ & M123R \\
\hline & c. $392 \mathrm{~T}>\mathrm{C}$ & L131P \\
\hline & c. $490 \mathrm{~T}>\mathrm{C}$ & W164R \\
\hline & c. $674 \mathrm{~A}>\mathrm{G}$ & Q225R \\
\hline & c. $947 \mathrm{~T}>\mathrm{G}$ & L316R \\
\hline & c. $985 \mathrm{~A}>\mathrm{G}$ & S329G \\
\hline & c.985_986AG $>C C$ & S329P \\
\hline Nonsense & c. $624 \mathrm{G}>\mathrm{A}$ & W208X \\
\hline \multirow[t]{5}{*}{ Deletion } & c.91_92 del AC & FS/190X \\
\hline & c.521delA & $\mathrm{FS} / 211 \mathrm{X}$ \\
\hline & c.1055_1068delGTCCCCAAGATGAG & FS/376X \\
\hline & 5'UTR-AVPR2_DEL 4,586 & $\begin{array}{c}\text { Large del of } \\
\text { AVPR2 }\end{array}$ \\
\hline & 5'UTR-AVPR2_DEL 32,787 & $\begin{array}{l}\text { Large del of } \\
\text { AVPR2 }\end{array}$ \\
\hline \multirow[t]{3}{*}{ Insertion } & c.369_370insT & FS/191X \\
\hline & c.498_499insTC & $\mathrm{FS} / 212 \mathrm{X}$ \\
\hline & c.738_739insG & $\mathrm{FS} / 257 \mathrm{X}$ \\
\hline
\end{tabular}

mutation with complete NDI symptoms. S329P was found in a boy with complete NDI, and his mother was an asymptomatic heterozygous carrier. Another mutation on Ser329, S329R, has been reported [21].

A nonsense mutation, W208X, was observed in a boy with complete NDI, and his asymptomatic mother and sister were heterozygous carriers of the mutation. To date, all reported nonsense mutations have been shown causative [19].

Five novel deletion mutations were found, and all these mutations cause either large losses of the gene, including the $5^{\prime}$ untranslated region (two families), or frame shifts that result in premature truncation (two families) or 
elongation (one family) of the coded proteins (Table 3). In a family with a 32,787 nucleotides deletion (the exact deletion size was determined in Daniel Bichet's lab in Montreal), two affected brothers showed complete NDI. Their mother and sister were asymptomatic heterozygous carriers of the mutation. In another family having a large deletion (4,586 nucleotides), a boy was affected with complete NDI and his mother was a heterozygous carrier. A 1-nucleotide deletion was observed in a complete NDI boy, and his mother was a heterozygous carrier of the mutation. In two families having 2-nucleotide or 14-nucleotide deletion mutations, the index patients were females who were diagnosed as having complete NDI after stimulation tests.

Three novel small (1-2 nucleotides) frame-shift insertion mutations were found in three families in which the index patients were males with complete NDI. All of these mutations are expected to introduce a premature stop codon, and the mutations were conserved within the families (Table 3).

Frequency of symptomatic carriers of AVPR2 mutations

Carriers of disease-causing mutations of AVPR2 (females having heterozygous mutations) sometimes manifest NDI symptoms [22, 23]; however, it is unknown how often this event occurs. In our present study, in 52 NDI families with AVPR2 mutations, at least one female member (usually a mother of an affected boy) were genetically analyzed and found to have the disease-causing allele. In a total of 64 such female subjects, $16(25 \%)$ had symptoms of polyuria and polydipsia, while $43(67 \%)$ were asymptomatic. Among the 16 symptomatic female subjects, 4 were diagnosed as having complete NDI, and 3 were the probands in each family. The types of mutations identified in these symptomatic carriers were: missense mutations (8), deletion mutations (6), nonsense mutation (1), and insertion mutation (1), indicating that this event occurs in any type of mutation.

The mechanism for the appearance of NDI symptoms in female carriers is explained by an extremely skewed inactivation of the normal allele of the X chromosome [24]; the frequency of this event was estimated to be very rare [9]. However, a recent study by Sato et al. [25] showed that a moderately skewed inactivation of the normal allele is enough to cause NDI symptoms. This result implies that symptomatic female carriers occur more often than previously thought. Our data are consistent with this speculation, and show that one fourth of carriers of AVPR2 disease-causing mutations present NDI symptoms. Thus, female patients with NDI symptoms require a careful examination, and gene mutation analysis for AVPR2 should be considered if other causes are unlikely.
AQP2 mutations causing NDI

Nine AQP2 mutations were identified in 9 NDI families (Table 4). The results from 3 of these families were previously reported [12]. These three families had monoallelic frame-shift deletion mutations (1-10 nucleotides) in the C-terminus of AQP2 (different mutations in each family), and showed an autosomal dominant inheritance with a slightly milder form of NDI [12]. The remaining six families were newly analyzed in the present study, and 6 different NDI-causing mutations were found (Table 4). These mutations consisted of 3 missense mutations and 3 deletion mutations (1-2 nucleotides deletions); 3 of them were novel mutations, and other three were recurrences of previously known mutations. Two missense mutations and one deletion mutation showed a recessive inheritance mode, while one missense mutation and two small deletion mutations manifested a dominant inheritance mode.

The family trees and results of mutation analysis of newly analyzed families are summarized in Fig. 1. In family 1, two missense mutations (A19V and G29S) were compound heterozygous in a male NDI patient and manifested by vasopressin-unresponsive polyuria (8-10 L/day). The patient's parents were asymptomatic. The father carried a novel A19V mutation, while the mother had a G29S mutation, which was previously reported to be causative [26]. In family 2, the G29S mutation (the same one found in family 1) was homozygous in the proband,

Table 4 Disease-causing $A Q P 2$ mutations

\begin{tabular}{|c|c|c|c|}
\hline Nucleotide change & $\begin{array}{l}\text { Amino } \\
\text { acid } \\
\text { change }\end{array}$ & $\begin{array}{l}\text { Inheritance } \\
\text { mode }\end{array}$ & References \\
\hline \multicolumn{4}{|l|}{ Newly analyzed } \\
\hline \multicolumn{4}{|l|}{ Missense mutations } \\
\hline c. $56 \mathrm{C}>\mathrm{T}$ & A19V & Recessive & New \\
\hline c. $85 \mathrm{G}>\mathrm{A}$ & G29S & Recessive & $\begin{array}{l}\text { Sahakitrungruang } \\
\text { et al. [26] }\end{array}$ \\
\hline c. $761 \mathrm{G}>\mathrm{A}$ & $\mathrm{R} 254 \mathrm{Q}$ & Dominant & $\begin{array}{l}\text { Savelkoul et al. } \\
\text { [28] }\end{array}$ \\
\hline \multicolumn{4}{|l|}{ Deletion mutations } \\
\hline c.127_128delCA & FS/105X & Recessive & Tajima et al. [27] \\
\hline c.750delG & $\mathrm{FS} / 334 \mathrm{X}$ & Dominant & New \\
\hline c.775delC & $\mathrm{FS} / 334 \mathrm{X}$ & Dominant & New \\
\hline \multicolumn{4}{|l|}{ Previously analyzed } \\
\hline \multicolumn{4}{|l|}{ Deletion mutations } \\
\hline c. $721 \mathrm{delG}$ & $\mathrm{FS} / 334 \mathrm{X}$ & Dominant & $\begin{array}{l}\text { Kuwahara et al. } \\
\text { [12] }\end{array}$ \\
\hline c.763-772del & $\mathrm{FS} / 331 \mathrm{X}$ & Dominant & $\begin{array}{l}\text { Kuwahara et al. } \\
\text { [12] }\end{array}$ \\
\hline c.812-818del & $\mathrm{FS} / 332 \mathrm{X}$ & Dominant & $\begin{array}{l}\text { Kuwahara et al. } \\
\text { [12] }\end{array}$ \\
\hline
\end{tabular}




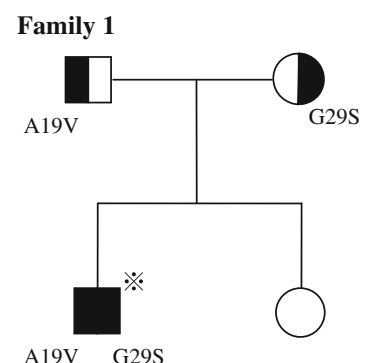

Family 2

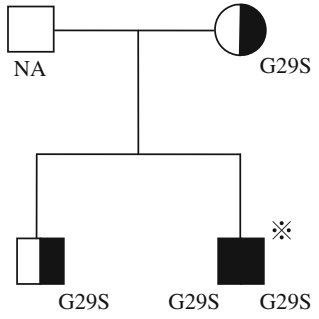

Family 3

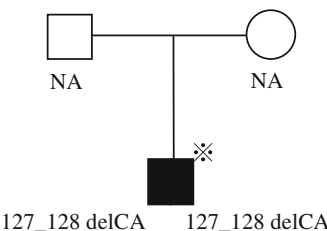

Family 4

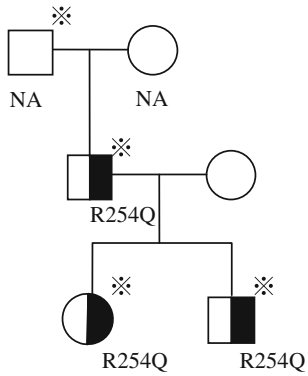

Family 5
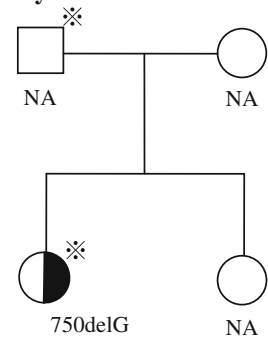

NA

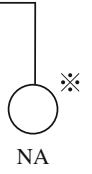

Family 6

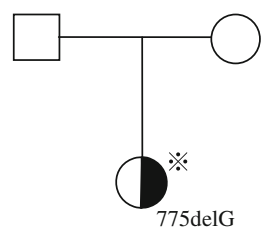

NA ; gene analysis not available ※, showing NDI symptoms

Fig. 1 AOP2 mutations newly found in Japanese NDI families. Six different AQP2 mutations were found in six Japanese NDI families. $N A$ gene analysis not available. *Showing NDI symptoms

and his healthy mother and brother were heterozygous for the mutation. The patient exhibited polyuria (urine volume was 10-15 L/day), and the urine osmolality did not respond to vasopressin (maximum urine osmolality was about $100 \mathrm{mOsm} / \mathrm{L}$ ). The appearance of NDI symptoms only when the mutations are compound heterozygous or homozygous strongly indicates that these two missense mutations are disease causative.

In family 3, a homozygous 2-nucleotide deletion mutation (c.127_128delCA) was found in a neonatal boy who exhibited polyuria and dehydration. His urine osmolality did not respond to vasopressin $(<150 \mathrm{mOsm} / \mathrm{L})$. The resultant frame shift predicts new amino acids starting at codon 43 , with a premature stop at codon 105 . The same mutation was found in an unrelated Japanese family and has been reported by others [27].

In family 4, a monoallelic R254Q mutation was found in two siblings and their father. The father and paternal relatives had NDI symptoms, but have not been clinically examined. The siblings (a 1-year-old boy and a 3-year-old girl) showed similar clinical characteristics of polyuria and polydipsia starting 4-6 months after birth, and slight responsiveness of urine osmolality to vasopressin (maximum urine osmolality was about $500 \mathrm{mOsm} / \mathrm{L}$ after vasopressin administration). Consistent with these observation, this mutation (R254Q) was recently reported as an NDI causative mutation with dominant inheritance [28]. Another missense mutation on this residue, R254L, was also reported to cause a similar NDI phenotype [29]. In the heterologous expression studies, the R254Q-AQP2 protein was impaired in its AVP-elicited phosphorylation of Ser256, which is a key step for AQP2 trafficking to the apical membrane [28]. The dominant inheritance can be explained by hetero-oligomerization of wild-type/mutant AQP2 proteins and dominant-negative effect of mutant protein on wild-type protein [7].

In a female patient of family 5, a novel heterozygous 1-nucleotide deletion mutation (750delG) was found. The patient's sister and father were symptomatic. Her urine osmolality did not respond to vasopressin. This mutation causes a frame shift, with a new amino acids sequence starting from Val251 and ending at codon 334 in the C-terminal of AQP2. In Family 6, a 2-year-old girl was found to have a novel heterozygous 1-nucleotide deletion mutation (775delC) that causes frame shift with a new C-terminus starting at Leu259. The parents did not show NDI symptoms and did not carry the mutation, which indicated that the mutation occurred de novo. The girl showed polyuria and polydipsia and NDI was diagnosed by water deprivation and vasopressin administration tests. These identified two deletion mutations cause frame shifts from Val251 and Leu259 and a new C-terminal tail ending at codon 334 (Table 4). We previously reported three small deletion mutations in the C-terminus that cause similar frame shifts and show dominant inheritance [12] (Table 4). These frame-shift mutations share the loss of the last tail of the AQP2 protein, the site where PDZ proteins and ubiquitines interact, and the presence of extended C-terminal tails that contain missorting signals. As a result of these effects, these mutant AQP2 proteins making tetramers with wild-type proteins are incorrectly translocated to the basolateral membrane instead of the apical membrane [20, 30, 31]. This missorting is confirmed in knockin mice harboring a human C-terminal deletion mutation (c.763-772del) [32]. It is interesting that these deletion mutations are observed more often that missense mutations in Japanese patients, which is different from the frequencies in a total global summary [3, 20].

We could not detect mutations in the two genes in seven families ( $9 \%$, Table 1$)$. It is said that causative gene mutations cannot be found in approximately $5 \%$ of all 
congenital NDI patients [4]. Possibilities such as the presence of mutations in the promoter regions of the AVPR2 or AQP2 genes are a likely explanation [4]. Our mutational analysis does not usually cover the promoter regions; thus, this possibility remains to be examined. To date, no genes other than AVPR2 and AQP2 have been attributed to NDI. However, it is possible that mutations in the genes encoding signaling cascade molecules connecting these two key membrane proteins cause NDI. Progress in gene mutational analysis methods such as whole-exome sequencing will address this possibility.

Acknowledgments We thank Mieko Goto for technical assistance and Dr. Daniel Bichet for help in mutation analysis. We thank Drs. M. Asai, A Ashida, T. Aso, T. Hamajima, T. Hasegawa, M. Hayashi, D. Hirano, K. Ichida, E. Ihara, M. Iketani, T. Imanishi, H. Ishiguro, T. Ishii, S. Ishikawa, K. Iwai, I. Kamimura, K. Kamoi, M. Kawamura, E. Kawatani, H. Kobayashi, H. Komatsu, K. Kuryu, Y. Mase, T. Matsumoto, H. Matsuoka, S. Minowa, H. Mizuno, S. Murakami, S. Murao, K. Muroya, K. Niimi, Y. Nishibori, M. Nishida, E. Noguchi, E. Ogawa, T. Ooeda, C. Osugi, M. Ohta, H. Onishi, F. Otiai, N. Otsuka, H. Ozaki, K. Saijyou, N. Sasaki, F. Sato, K. Satomura, M. Shoji, S. Takakuwa, T. Takayanagi, F. Takemoto, S. Tamura, S. Tanigawa, M. Uehara, O. Uemura, N. Ura, and T. Yamauchi for referring NDI patients to us.

\section{Conflict of interest None.}

\section{References}

1. Morello JP, Bichet DG. Nephrogenic diabetes insipidus. Annu Rev Physiol. 2001;63:607-30.

2. Sasaki S. Nephrogenic diabetes insipidus: update of genetic and clinical aspects. Nephrol Dial Transpl. 2004;19:1351-3.

3. Babey M, Kopp P, Robertson GL. Familial forms of diabetes insipidus: clinical and molecular characteristics. Nat Rev Endocrinol. 2011;7:701-14.

4. Wesche D, Deen PM, Knoers NV. Congenital nephrogenic diabetes insipidus: the current state of affairs. Pediatr Nephrol. 2012. PubMed PMID: 22427315.

5. Birnbaumer M, Seibold A, Gilbert S, Ishido M, Barberis C, Antaramian A, et al. Molecular cloning of the receptor for human antidiuretic hormone. Nature. 1992;357:333-5.

6. Fushimi K, Uchida S, Hara Y, Hirata Y, Marumo F, Sasaki S. Cloning and expression of apical membrane water channel of rat kidney collecting tubule. Nature. 1993;361:549-52.

7. Loonen AJ, Knoers NV, van Os CH, Deen PM. Aquaporin 2 mutations in nephrogenic diabetes insipidus. Semin Nephrol. 2008;28:252-65.

8. Noda Y, Sohara E, Ohta E, Sasaki S. Aquaporins in kidney pathophysiology. Nat Rev Nephrol. 2010;6:168-78.

9. Sasaki S, Fushimi K, Saito H, Saito F, Uchida S, Ishibashi K, et al. Cloning, characterization, and chromosomal mapping of human aquaporin of collecting duct. J Clin Invest. 1994;93: 1250-6.

10. Deen PM, Verdijk MA, Knoers NV, Wieringa B, Monnens LA, van $\mathrm{Os} \mathrm{CH}$, et al. Requirement of human renal water channel aquaporin-2 for vasopressin-dependent concentration of urine. Science. 1994;264:92-5.

11. Arthus MF, Lonergan M, Crumley MJ, Naumova AK, Morin D, De Marco LA, et al. Report of 33 novel AVPR2 mutations and analysis of 117 families with X-linked nephrogenic diabetes insipidus. J Am Soc Nephrol. 2000;11:1044-54.

12. Kuwahara M, Iwai K, Ooeda T, Igarashi T, Ogawa E, Katsushima $\mathrm{Y}$, et al. Three families with autosomal dominant nephrogenic diabetes insipidus caused by aquaporin-2 mutations in the C-terminus. Am J Hum Genet. 2001;69:738-48.

13. Owada M, Kawamura M, Kimura Y, Fujiwara T, Uchida S, Sasaki S, et al. Water intake and 24-hour blood pressure monitoring in a patient with nephrogenic diabetes insipidus caused by a novel mutation of the vasopressin V2R gene. Intern Med. 2002; 41:119-23.

14. Mizuno H, Sugiyama Y, Ohro Y, Imamine H, Kobayashi M, Sasaki S, et al. Clinical characteristics of eight patients with congenital nephrogenic diabetes insipidus. Endocrine. 2004;24: 55-9.

15. Ashida A, Yamamoto D, Nakakura H, Matsumura H, Uchida $S$, Sasaki S, et al. A case of nephrogenic diabetes insipidus with a novel missense mutation in the AVPR2 gene. Pediatr Nephrol. 2007;22:670-3.

16. Fujimoto M, Imai K, Hirata K, Kashiwagi R, Morinishi Y, Kitazawa $\mathrm{K}$, et al. Immunological profile in a family with nephrogenic diabetes insipidus with a novel $11 \mathrm{~kb}$ deletion in AVPR2 and ARHGAP4 genes. BMC Med Genet. 2008;9:42.

17. Bichet DG, Birnbaumer M, Lonergan M, Arthus MF, Rosenthal W, Goodyer P, et al. Nature and recurrence of AVPR2 mutations in X-linked nephrogenic diabetes insipidus. Am J Hum Genet. 1994;55:278-86.

18. Bichet DG, Arthus MF, Lonergan M, Hendy GN, Paradis AJ, Fujiwara TM, et al. X-linked nephrogenic diabetes insipidus mutations in North America and the Hopewell hypothesis. J Clin Invest. 1993;92:1262-8.

19. Spanakis E, Milord E, Gragnoli C. AVPR2 variants and mutations in nephrogenic diabetes insipidus: review and missense mutation significance. J Cell Physiol. 2008;217:605-17.

20. Sasaki S. Aquaporin 2: from its discovery to molecular structure and medical implications. Mol Asp Med. 2012;33:535-46.

21. Faerch M, Christensen JH, Corydon TJ, Kamperis K, de Zegher $\mathrm{F}$, Gregersen N, et al. Partial nephrogenic diabetes insipidus caused by a novel mutation in the AVPR2 gene. Clin Endocrinol (Oxf). 2008;68:395-403.

22. Moses AM, Sangani G, Miller JL. Proposed cause of marked vasopressin resistance in a female with an X-linked recessive V2 receptor abnormality. J Clin Endocrinol Metab. 1995;80:1184-6.

23. van Lieburg AF, Verdijk MA, Schoute F, Ligtenberg MJ, van Oost BA, Waldhauser F, et al. Clinical phenotype of nephrogenic diabetes insipidus in females heterozygous for a vasopressin type 2 receptor mutation. Hum Genet. 1995;96:70-8.

24. Nomura Y, Onigata K, Nagashima T, Yutani S, Mochizuki H, Nagashima K, et al. Detection of skewed X-inactivation in two female carriers of vasopressin type 2 receptor gene mutation. J Clin Endocrinol Metab. 1997;82:3434-7.

25. Satoh M, Ogikubo S, Yoshizawa-Ogasawara A. Correlation between clinical phenotypes and $\mathrm{X}$-inactivation patterns in six female carriers with heterozygote vasopressin type 2 receptor gene mutations. Endocr J. 2008;55:277-84.

26. Sahakitrungruang T, Wacharasindhu S, Sinthuwiwat T, Supornsilchai V, Suphapeetiporn K, Shotelersuk V. Identification of two novel aquaporin-2 mutations in a Thai girl with congenital nephrogenic diabetes insipidus. Endocrine. 2008;33:210-4.

27. Tajima T, Okuhara K, Satoh K, Nakae J, Fujieda K. Two novel aquaporin-2 mutations in a sporadic Japanese patient with autosomal recessive nephrogenic diabetes insipidus. Endocr J. 2003; 50:473-6.

28. Savelkoul PJ, De Mattia F, Li Y, Kamsteeg EJ, Konings IB, van der Sluijs P, et al. p.R254Q mutation in the aquaporin-2 water channel causing dominant nephrogenic diabetes insipidus is due 
to a lack of arginine vasopressin-induced phosphorylation. Hum Mutat. 2009;30:E891-903.

29. de Mattia F, Savelkoul PJ, Kamsteeg EJ, Konings IB, van der Sluijs P, Mallmann R, et al. Lack of arginine vasopressin-induced phosphorylation of aquaporin-2 mutant AQP2-R254L explains dominant nephrogenic diabetes insipidus. J Am Soc Nephrol. 2005;16:2872-80.

30. Asai T, Kuwahara M, Kurihara H, Sakai T, Terada Y, Marumo F, et al. Pathogenesis of nephrogenic diabetes insipidus by aquaporin-2 C-terminus mutations. Kidney Int. 2003;64:2-10.
31. Kamsteeg EJ, Bichet DG, Konings IB, Nivet H, Lonergan M, Arthus MF, et al. Reversed polarized delivery of an aquaporin-2 mutant causes dominant nephrogenic diabetes insipidus. J Cell Biol. 2003;163:1099-109.

32. Sohara E, Rai T, Yang SS, Uchida K, Nitta K, Horita S, et al. Pathogenesis and treatment of autosomal-dominant nephrogenic diabetes insipidus caused by an aquaporin 2 mutation. Proc Natl Acad Sci USA. 2006;103:14217-22. 